\title{
Predicting the Probability of Spectrum Sensing with LMS Process in Heterogeneous LTE Networks
}

\author{
Mohammed Hicham HACHEMI, Mohammed FEHAM, Harroun Errachid ADARDOUR \\ STIC Laboratory, Dept. of Telecommunications, Abou-Bekr Balkaid University, Tlemcen, Algeria \\ m.h_hachemi@yahoo.fr,feham_m@yahoo.fr, haroun-errachid.adardour@mail.univ-tlemcen.dz
}

Manuscript received May 16, 2016

\begin{abstract}
Mobile communication systems present an actuality subject in academic and industrial research activities due to several phenomena such as interferences, multipath, fading and shadowing. All this lead to a severe perturbation on handover mechanism which depends on specific reports, essentially, reference signal received power (RSRP) and signal-to-interference and noise ratio (SINR). In this paper, we design a new technique in handover domain; it consists of combining energy detection method used in cognitive radio with least mean square (LMS) process in order to prognosticate the handover impact in a realistic scenario of heterogeneous LTE network. More exactly, technique sense of the word "triggering" will be changed to a probability of detection. The proposed algorithm cycle follows two main steps; Firstly, predict at what time the absence of spectrum (primary user) will occur, using a predicted sensing probability. Secondly, search others spectrums in this time by calculating the probability of detection for each sensed signal and hand-off secondary user in the best spectrum. The results achieved of the simulation are evaluating, it shows that the proposed method predict the original probability of detection correctly with minimal errors and select the best spectrum successfully contraly to standard handover process.
\end{abstract}

\section{Keywords}

Adaptive filters, LMS process, LTE/LTE-A, energy detection, handover, spectrum sensing

\section{Introduction}

In recent decades, the demand for mobile applications to high data rate continues to increase. Several mobile networks generations have known a lightning evolution such as $3^{\text {rd }}$ generation partnership project long term evolution (3GPP LTE) and LTE-Advanced (LTE-A) technologies [1-3], marketed as $4^{\text {th }}$ generation in telecommunication systems. The 3GPP standardizes the multiple access technologies in downlink as orthogonal frequency division multiple access (OFDMA), and single carrier frequency division multiple access (SCFDMA) in uplink [1], [3], [4], [5]. These techniques aim to give high peak data rates, improve network capacity and coverage, high spectral efficiency, and spectrum flexibility [6], [7], [8]. Therefore, researchers' community focus their efforts on the enhancement of spectral efficiency and throughput in nextgeneration wireless networks with deploying small-cell also known as femto-cell, or a home evolved node-B (HeNB). Their objective is to extend indoor coverage where in most cases the signal strength from outdoor evolved node-B (eNB) is insufficient.

Due to economic reasons, the deployments of femtocells promise a cost efficient solution in communications infrastructure. They guarantee an improved indoor coverage, higher transmission rate, better spectrum reuse, maintain the requirements for quality of service (QoS) and so on. Fundamentally, HeNBs are deployed in an apartment or an office to alleviate the loading of the overlay macro-cell, and to enhance the communications of femto/macro-users.

Many critical parameters and problematic for radio frequency (RF) spectrum measurement in LTE/LTE-A require efficient utilization; same RSRP and SINR, whose study and optimization become indispensable for maintaining a continuity of service. The RSRP is the most basic measurement performed by the physical layer of user equipment (UE); it is used as an input for cell resection and handover decisions [9]. The RSRP is defined as the average power of the resource elements (REs) that carry cellspecific reference signals (RSs) over the entire bandwidth [10]. Whereas the SINR is defined as the ratio of the signal power to the summation of the average interference power from other cells and the background noise [9].

When a UE is moving from one cell to another it triggers the procedure of mobility management, known as handover process; it is one of the key components in cellular network mobility management [11] but also a crucial point. Basically, handover types are divided into hard or soft handovers [2]. In the first case, also known as breakbefore-make, the channel is released from the source cell and only then will engage to make a channel at the target cell. While in soft handover (make-before-break), the channel is retained at the source cell and used for a certain time; in parallel, it makes the tunnel with the channel at the 
target cell. So, hard handover has been adopted in LTE/LTE-A systems by 3GPP [2], [12], [13]. Its use reduces handover mechanism complexity due to LTE/LTE-A networks architecture and minimizes the handover delay. However, hard handover approach causes a very strong impact on applications that may result a lost data during a session, and it is not acceptable for UEs.

Several articles have been published in mobility management and spectrum sensing areas. However, authors of reference [2] present an excellent survey in LTE/LTE-A where they clarify the challenges and issues on handover management and class the recent works into four groups based on the nature of these algorithms: 1) Location based algorithms; use the actual location of HeNBs as an input parameter to emend the handover efficiency. 2) Mobility or speed based algorithms; the UE's velocity should be taken into account during the handover decision. 3) Policy based decision algorithms; some predefined policy was placed to make the adequate decision. Lastly, 4) learn based algorithms; apply some learning skills to harvest some information from the environment and to use it to improve good decisions.

In [14], the authors explain the issue where one macro-cell has several femto-cell implying that they will have a large number of unnecessary macro-to-femto cell handovers when mobile users move with low velocity. The idea is to maintain macro-cell connection rather than to trigger the handover by identifying «femto-cell temporary visitors» where they divided femto-cell area and its surroundings into sub-areas using positioning technology and predict next sub-area movement patterns when a mobile user approaches the femto-cell.

The works in [15] take UEs' speeds for handover decision into account where UEs move with high velocities. This situation increases significantly the numbers of handovers which affect communication quality. To reduce the unnecessary handovers due to the limitation of spectrum resource by serving the station, they introduced in addition to SINR, a periodic scan mechanism. They present two flow charts. If the serving station is macro-cell, we use both SINR trigger and regular scans. Otherwise, if the serving station is femto-cell we use only SINR trigger scan.

The paper [16] presents two issues. Firstly, oversized neighboring eNB list problem, when UE needs to handoff, it uses a long time for measuring all stations (eNBs and HeNBs) on the list to select a suitable station (eNB or HeNB). But due to the short transmission range of HeNBs, most of stations in the list are out of range. This procedure is known as senseless measurement. Secondly, HeNB idleness problem, where UE stay connected on eNB and cannot use the signal strength provided by HeNB. To avoid these two issues, the authors propose the location-based neighboring eNB management scheme to alleviate the senseless measurement problem by decreasing the size of neighboring eNB list and the message flow of "HeNBassisted HandOver".

Moreover, the reliability of signal detection is limited by attenuation due to path loss, fading and shadowing [17]. Sensing algorithms in cognitive radio are seen as a solution improving the spectrum utilization. There are several studies proposed in sensing algorithms for detecting primary user (eNodeB/HeNB) by secondary user (UE) such as energy detection, wavelet-based detection, cycle stationary feature detection and matched filtering [18]-[20].

Gentner et al. [21] present a novel analytical derivation of the false alarm probability (FAP) and detection probability (DP) for non-line of sight (NLOS) detection based on LTE signals. The concept builds on [2], where the authors present a derivation of the FAP and DP of detecting pilot bursts of W-CDMA systems.

In reference [22], the authors present the spectrum sensing issue in the case when primary and secondary systems operate on a similar scale in terms of transmission power. They proposed an analytic model based on sensors network and energy detection. The numerical results are evaluated in two different scenarios when the primary system is a wireless local area network (WLAN) and a 3GPP LTE network.

The authors in [23] propose a method for LTE signal detection based on constant amplitude zero autocorrelation (CAZAC) sequence. They introduced and calculated CAZAC sequence with fractional Fourier transform (FrFT) instead fast Fourier transform (FFT) method. The simulation results of the probability of detection are compared to the four methods; energy detection, FrFT, CAZAC and cyclic prefix.

Mobility management, scarcity of radio resources, dynamic nature of propagation environment, a variety of user mobility and heterogeneous networks are the biggest challenges that give birth to the proposed technique. The principle is in two phases; First phase; foresee the moment where the absence of primary user spectrum (HeNBs or eNBs) will occur, using energy detection technique that is represented by a probability of detection $P_{\mathrm{d}}$, with an estimator known as the LMS process. Second phase; find other spectrums of primary users in this time by calculating their $P_{\mathrm{d}}$ and select the best spectrum, in order to prepare and connect the secondary user. We employ all this for real mobility settings in a heterogeneous LTE network (femto and macro cells).

The rest of paper is arranged as follows. Section 2 introduces the system model of LMS mechanism, propagation model used in LTE and the functioning of energy detection. Section 3 presents the relationship between the conventional handover procedure and proposed algorithm. Section 4 provides simulation results for both methods and we conclude by Sec. 5 with the conclusion and future works that follow this research. 


\section{System Model}

\subsection{LMS Process}

It is considered as a promising element in signal processing applications because of its simplicity and good performance on the future state of a system.

LMS filter supervises prediction error $e(n)$ and attempts to minimize the mean squared prediction error $E\left\{e(n)^{2}\right\}$ by updating the weight vector of prediction $\mathbf{W}_{n}$. However, a $p^{\text {th }}$ order LMS predictor is represented by:

$$
\hat{x}(n+p)=\sum_{l=0}^{p-1} w(l) x(n-l)=\mathbf{W}_{n}^{\mathrm{T}} \mathrm{X}(n)
$$

where $p$ is the prediction order, $\mathbf{X}(n)$ the input vector and $\mathbf{W}_{n}$ denotes the coefficient vector (or the weighting vector), where:

$$
\begin{gathered}
\mathbf{X}(n)=[x(n), x(n-1), \cdots, x(n-p+1)]^{\mathrm{T}}, \\
\mathbf{W}_{n}=\left[w_{n}(0), w_{n}(1), \cdots, w_{n}(p-1)\right]
\end{gathered}
$$

knowing that $\mathrm{T}$ represents the transposed.

Normalized LMS (NLMS) is frequently used in practice. It is the modification of the LMS algorithm where the update equation is changed as:

$$
\mathbf{W}_{n+1}=\mathbf{W}_{n}+\mu \times e(n) \times\left(\mathbf{X}(n) /\|\mathbf{X}(n)\|^{2}\right) .
$$

So, the expression of prediction error $e(n)$ is defined as:

$$
e(n)=x(n+p)-\hat{x}(n+p) .
$$

If at the time $n$, the value of $x(n+p)$ is not available to compute $e(n)$, we can use $e(n-p)$ instead $e(n)$ [24]:

$$
e(n-p) \approx x(n)-\hat{x}(n)
$$

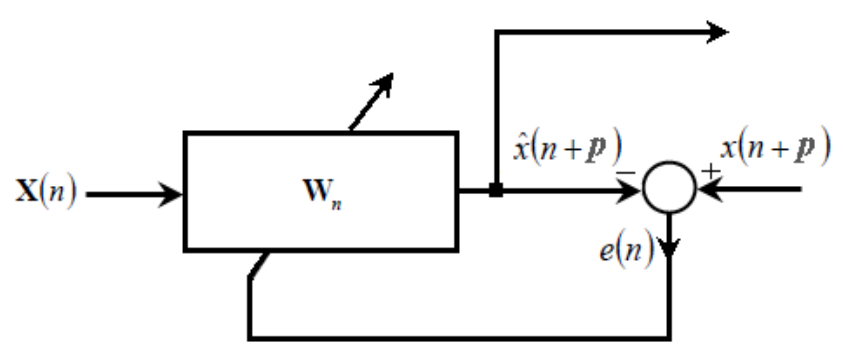

Fig. 1. Principle diagram of LMS filter.

Stability of NLMS is controlled by a fixed step-size constant $\mu$, which also controls the rate of convergence (speed of tracking). In a normalized LMS, if $0<\mu<2$, then LMS filter will converge to the mean. The prediction linear operation by LMS process is shown in Fig. 1.

\subsection{Propagation Model}

In order to have a probability of detection, we must have RSRP model. This model is modeled by the mathe- matical equations in a heterogeneous LTE network composed of macro and femto cells.

$R S R P$ is calculated from the transmit power $P_{\mathrm{c}}$, path loss values from cell transmitting to user equipment $P L_{\mathrm{c}, \mathrm{ue}}$ and additional shadow fading with a log-normal distribution and a standard deviation $P L_{\mathrm{c}, \text { fad }}$ [9], [12], [25], [26], [27]. It is represented as follows:

$$
R S R P_{\mathrm{c}, \mathrm{ue}}=P_{\mathrm{c}}-P L_{\mathrm{c}, \mathrm{ue}}-P L_{\mathrm{c}, \mathrm{fad}} .
$$

Two path loss propagations models are used to calculate $R S R P_{\mathrm{c}, \text { ue }}$ in this paper:

- The $R S R P_{\text {macro,ue }}$ for macro-cell transmitter (eNB) and an outdoor macro-user (MU).

- The $R S R P_{\text {femto,ue }}$ for femto-cell transmitter (HeNB) and an outdoor femto-user (FU) associated to indoor HeNB.

Firstly, $R S R P_{\text {macro,ue: The macro-cell propagation }}$ model for a MU that roams in outdoor urban area $P L_{\text {macro,ue }}$ can be expressed in $\mathrm{dB}$ [28], [29], [30], [31] as:

$$
P L_{\text {macro,ue }}=2.7+42.8 \log _{10}(R)
$$

where $R$ is the distance between an eNB and a MU in meters.

In the case where we have an indoor $\mathrm{MU}$, we add $L_{\mathrm{ow}}$ in (8) that represents the penetration loss of an outdoor wall. The result of the path loss in $\mathrm{dB}$ is given by:

$$
P L_{\text {macro,ue }}=2.7+42.8 \log _{10}(R)+L_{\text {ow }} .
$$

The log-normal shadowing path loss model $P L_{\text {macro,fad }}$ is represented in $\mathrm{dB}$ by:

$$
P L_{\text {macroffad }}=P L_{0}+10 \beta \log _{10}\left(d / d_{0}\right)+X_{\sigma_{\text {macro }}} .
$$

$P L_{0}$ is the path loss at a reference distance $d_{0}$ measured in $\mathrm{dB}, \beta$ the path loss exponent without unit, $d$ is the separation distance between an eNB and a MU in meters and $X_{\sigma_{\text {macro }}}$ is a random variable Gaussian distribution with zero mean and the standard deviation $\sigma_{\text {macro }}$ in $\mathrm{dB}[32]$. The $P L_{0}$ is calculated by the free space path loss (FSPL) model as:

$$
P L_{0}=10 \log _{10}\left(4 \pi d_{0} / \lambda\right)^{2}
$$

where $\lambda$ is the wavelength of the signal in meters.

So thus, we will have:

$$
R S R P_{\text {macro,ue }}=P_{\text {macro }}-P L_{\text {macro,ue }}-P L_{\text {macro,fad }} .
$$

Secondly, $R S R P_{\text {femto,ue: }}$ The path loss $P L_{\text {femto,ue }}$ between a HeNB and a FU that are in the same apartment can be calculated in $\mathrm{dB}$ [28], [29], [30], [31] as:

$$
\begin{aligned}
P L_{\text {femto,ue }} & =38.46+20 \log _{10}(R)+ \\
& 0.7 d_{2 \mathrm{D} \text {,indoor }}+18.3 n^{((n+2) /(n+1)-0.46)}+q \cdot L_{\mathrm{iw}}
\end{aligned}
$$

where $0.7 d_{2 \mathrm{D} \text {,indoor }}$ represents the penetration loss due to walls inside an apartment (expressed in meters), $n$ is the 
number of building floors, $q$ is the number of walls separating apartments between the HeNB and the FU and $L_{\text {iw }}$ is the penetration loss due to internal building walls.

In this work, we consider that we have an outdoor FU associated to an indoor HeNB. We assume that:

- The HeNB is on the ground floor of an apartment $(n=0)$.

- There are no other barriers between the HeNB and FU apart $q=3$.

The equation of the path loss outdoor FU \& indoor HeNB propagation model is given by:

$$
\begin{aligned}
P L_{\text {femto,ue }} & =\max \left[P L_{\text {macro,ue }}, 38.46+20 \log _{10}(R)\right] \\
& +0.7 d_{2 \mathrm{D} \text {,indoor }}+q \cdot L_{\mathrm{iw}}+L_{\mathrm{ow}},
\end{aligned}
$$

concerning the log-normal shadowing path loss model $P L_{\text {femto,fad }}$ is the same equation for $P L_{\text {macro,fad }}$ except that the standard deviation $\sigma_{\text {femto }}$ is different.

Thereby, we will have:

$$
R S R P_{\text {femto,ue }}=P_{\text {femto }}-P L_{\text {femto,ue }}-P L_{\text {femto,fad }} .
$$

Now, observing SINR. In general, it can be calculated between $R S R P$ of the connected cell $R S R P_{\mathrm{c}, \text { ue }}$ and $R S R P$ value of the interfering cell plus the thermal noise

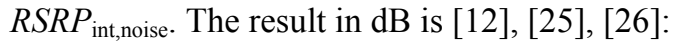

$$
S I N R_{\mathrm{ue}}=R S R P_{\mathrm{c}, \mathrm{ue}}-R S R P_{\mathrm{int}, \text { noise }} .
$$

In particular, we represent the SINR for a MU and a FU respectively with (17) and (18):

$$
\begin{aligned}
& S I N R_{\mathrm{MU}}=R S R P_{\text {macro,ue }}-R S R P_{\text {int,noise }}, \\
& S I N R_{\mathrm{FU}}=R S R P_{\text {femto,ue }}-R S R P_{\text {int,noise }} .
\end{aligned}
$$

\subsection{Energy Detection}

In this part, we interested on local spectrum sensing model as presented in [33]. The output of this method gives a decision value compared with $\rho$ that represents the decision of the energy threshold; if it is above the threshold, then the sensing of the primary user is present. Furthermore, the aim of this detection is to distinguish the following binary hypotheses [17], [34], [35], [36]

$$
\left\{\begin{array}{l}
H_{0, i}: y_{\mathrm{ue}_{i}}(t)=n_{i}(t) \\
H_{1, i}: y_{\mathrm{ue}_{i}}(t)=x_{\mathrm{eNB}}(t)+n_{i}(t)
\end{array}\right.
$$

where $y_{\mathrm{ue}_{i}}(t)$ is the received signal by $U E_{i}, x_{\mathrm{eNB}}(t)$ denotes the transmitted signal of an eNB, $n_{i}(t)$ represents the additive white Gaussian noise (AWGN) at $U E_{i} . H_{0, i}$ is a null hypothesis of $U E_{i}$ which defines the absence of $P U . H_{1, i}$ denotes the presence hypothesis of $U E_{i}$ that indicates the presence of $P U$ signal.

Assuming, we have one $U E$ to simplify scripture of (19). Now, $U E$ has two observations $H_{0}$ and $H_{1}$. It needs to take the decision between both over AWGN channel. Take $\mathrm{E}$ the energy of the received signal expressed by:

$$
\mathrm{E}=\int_{0}^{T} y_{\mathrm{ue}}^{2}(t) \mathrm{d} t=\frac{1}{2 T W} \sum_{n=1}^{2 T W} y_{n}^{2}
$$

where $T$ is the sensing time interval (or observation time interval) in seconds, $W$ bandwidth in $\mathrm{Hz}$.

For observations $H_{0}$, the energy detection is:

$$
\mathrm{E}_{0}=\frac{1}{2 T W} \sum_{n=1}^{2 T W} n_{n}^{2}
$$

For observations $H_{1}$, the energy sensing is written as:

$$
\mathrm{E}_{1}=\frac{1}{2 T W} \sum_{n=1}^{2 T W} x_{n}^{2}+n_{n}^{2}
$$

The decision statistic is shown to be central chi-square distributed with $2 T W$ degrees of freedom for $\mathrm{E}_{0}$ and for $\mathrm{E}_{1}$, no central chi-square distributed with $2 \mathrm{TW}$ degrees of freedom and a non-centrality parameter $2 \gamma$ where $\gamma$ represents the $\operatorname{SINR}[36]$ :

$$
\mathrm{E} \approx\left\{\begin{array}{l}
H_{0}: \chi_{2 T W}^{2} \\
H_{1}: \chi_{2 T W}^{2}(2 \gamma)
\end{array}\right.
$$

For this, the sensing metrics are presented such as the detection probability $P_{\mathrm{d}}$ and false alarm probability $P_{\mathrm{fa}}$ [18], [33], [34], [35], [36]:

$$
\begin{cases}\operatorname{Prob}\left(\mathrm{E}>\rho \mid H_{1}\right): & P_{\mathrm{d}}=Q_{\tau}(\sqrt{2 \gamma}, \sqrt{\rho}) \\ \operatorname{Prob}\left(\mathrm{E}>\rho \mid H_{0}\right): & P_{\mathrm{fa}}=\Gamma(\tau, \rho / 2) / \Gamma(\tau)\end{cases}
$$

where $Q_{\imath}(.,$.$) is the Marcum Q-function, \Gamma(.,$.$) represents$ the incomplete gamma function and $\Gamma($.$) the gamma$ function, $\tau$ is the time-bandwidth product [37], [38], [39].

\section{Standard and Proposed Handover Process in LTE}

In this section, the relationship between the standard handover procedure and the proposed algorithm in LTE are exposed.

\subsection{Conventional Handover Algorithm}

The standard handover algorithm in LTE is adopted to reduce the complexity of the LTE network architecture. It is also known as the LTE Hard Handover Algorithm. Two variables are essential for triggering handover process; handover margin (HOM) and time to trigger (TTT) timer. HOM is a constant value that represents the threshold to triggering the handover ( $\mathrm{HO})$. It is calculated by the difference of RSRP between the serving cell and targets cells that allows identifying the most appropriate target cell for UE. A TTT is required time for satisfying HOM condi- 


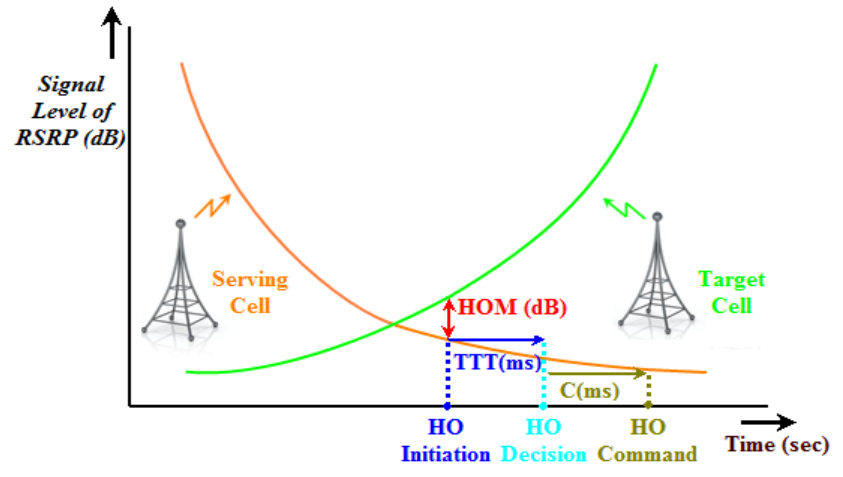

Fig. 2. Principle of the LTE hard handover process.

tion. The LTE Hard Handover condition is presented as follows [25], [40], [41], [42], [43], [44]:

$$
R S R P_{\mathrm{T}, \mathrm{ue}}>R S R P_{\mathrm{S}, \mathrm{ue}}+H O M
$$

where $R S R P_{\mathrm{T} \text {,ue }}$ and $R S R P_{\mathrm{S} \text {,ue }}$ are the RSRP received by a UE from the target cell and the serving sector, respectively.

As shown in Fig. 2, when equation (25) holds for a given TTT then the handover can be initiated, where the UE sends the measurement report to the eNB of the serving cell. The serving cell starts observing the incoming consecutive time slots after TTT starts. If the RSRP difference is less than or equal to HOM in any of the incoming consecutive time slots, the HO process will be reset, otherwise, handover process will be executed. This procedure is called the HO decision. Afterward, the preparation time is modeled as a constant protocol delay " $\mathrm{C}$ " in a millisecond. When the preparation has been completed, the serving cell sends the HO Command message to the UE in downlink (HO Command Process) [42]-[44].

\subsection{Proposed Algorithm}

Unlike the conventional handover algorithm (Fig. 3.a) that presents a problem on adjustment values HOM and TTT which can cause a false triggering of handover process due to several phenomena as multipath, fading and shadowing, the proposed technique aims to predict the triggering of handover process using estimate probability of detection method with LMS estimator.

The improvement brought to avoid this adjustments is to track RSRP signal automatically (Fig. 3.b), by estimating at what moment the sensing probability of link-down of serving cell will attain. Firstly, the proposed algorithm harvests $p$ samples of $R S R P_{\text {S, ue }}$ in order to predict the sample of $R S \hat{R} P_{\mathrm{S} \text {,ue }}$ at $t+p$. The next step consists to calculate $\hat{P}_{\mathrm{d} \text {,ue }}(t+p)$ by using $\operatorname{SIN}_{\mathrm{S} \text {,ue }}(t+p)$. When $\hat{P}_{\mathrm{d}_{\mathrm{S}, \mathrm{ue}}}(t+p)<P_{\mathrm{d}_{\mathrm{th}}}$ is fulfilled, the HO initiation is triggered followed by $\mathrm{HO}$ decision process that calculates the probabilities of detection for each sensed signal $P_{\mathrm{dT}_{i} \text {,ue }}(t)$. Then, the algorithm compares and selects the highest probability (best spectrum) and sends the HO Command message to the UE without waiting a constant protocol delay "C".

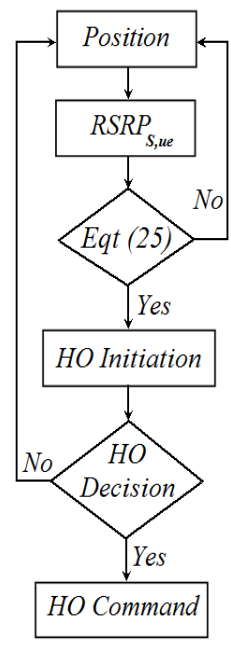

(a)

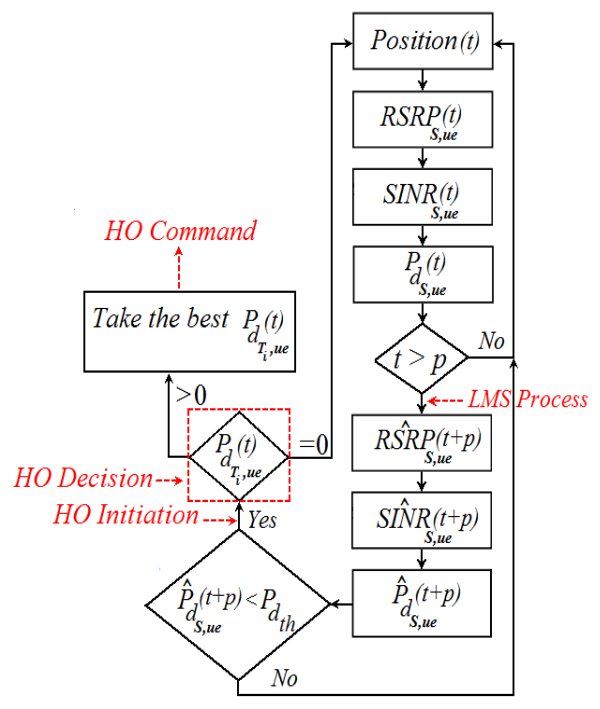

(b)
Fig. 3. a) LTE Hard handover algorithm.

b) Improved handover algorithm (proposed algorithm).

\section{Simulation Results}

In this section, we compare the two algorithms investigated in the same scenario using MATLAB platform. Table 1 provides the simulation parameters. This scenario is composed of one femto-cell (HeNB) and two macrocells (eNB). The HeNB is located in the eNB1. Seeing that, a femto-cell can support eight users [46].

By implementing the pedestrian mobility trace of Mobile and wireless communications Enablers for Twentytwenty (2020) Information Society (METIS) [45] in our topology model, we evaluate and interpret the simulation results.

Assuming that, the pedestrian starts to move in the femto-cell until the second macro-cell crossing the first macro-cell as shown in Fig. 4.

\subsection{Conventional Handover Process on Energy Detection}

The values of TTT and HOM for the LTE networks have already been specified by the 3GPP specification [47] where the specified values for TTT (in milliseconds) are 0 , $40,64,80,100,128,160,256,320,480,512,640,1024$, 1280,2560 and 5120. For HOM, the valid values vary between 0 and $10 \mathrm{~dB}$ with steps of $0.5 \mathrm{~dB}$, resulting in 21 valid $\mathrm{HOM}$ values. In our simulations, the HOM value for macro/femto cell set to $10 \mathrm{~dB}$ and we suppose the value of TTT plus the handover procedure equal to one second.

From the Fig. 5, the LTE hard handover process is triggered on two times. The first triggering, when the UE get into $\mathrm{HO}$ area at $t=96 \mathrm{~s}$, where the condition $R S R P_{\mathrm{eNB1} 1 \text {,ue }}>R S R P_{\mathrm{HeNB}, \text { ue }}+H O M$ holds for $T T T=512 \mathrm{~ms}$ and at $t=308 \mathrm{~s}$ is the second $\mathrm{HO}$ triggering. 


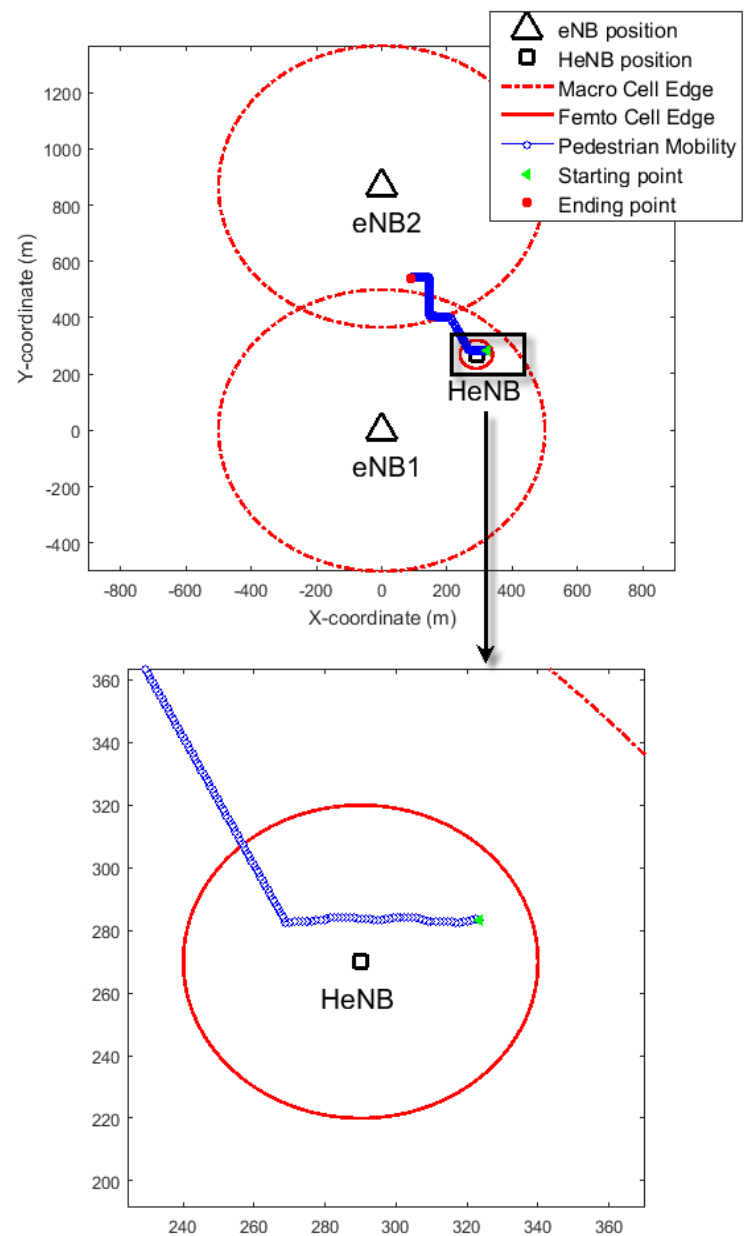

Fig. 4. Pedestrian's mobility METIS in our topology model.

\begin{tabular}{|c|c|}
\hline Parameter & Value \\
\hline Simulation time & $483 \mathrm{sec}$ \\
\hline Simulation area & $1000 \mathrm{~m} \times 1850 \mathrm{~m}$ \\
\hline UEs' numbers & 1 \\
\hline Macro-cell radius & $500 \mathrm{~m}$ \\
\hline Femto-cell radius & $50 \mathrm{~m}$ \\
\hline Frequency & $2 \mathrm{GHZ}$ \\
\hline Path loss exponent & 3 \\
\hline Reference distance & Starting UE's point \\
\hline Outdoor penetration loss & $20 \mathrm{~dB}$ \\
\hline Indoor penetration loss & $5 \mathrm{~dB}$ \\
\hline Transmit power of the eNB & $46 \mathrm{dBm}$ \\
\hline Transmit power of the HeNB & $23 \mathrm{dBm}$ \\
\hline Wavelength of the radio signal & $0.124 \mathrm{~m}$ \\
\hline $\begin{array}{c}\text { \# of walls separating apartment } \\
\text { between HeNB / UE }\end{array}$ & 3 \\
\hline UE's mobility & $\begin{array}{l}\text { Pedestrian mobility - } \\
\text { METIS trace }\end{array}$ \\
\hline Observation channel & AWGN \\
\hline $\begin{array}{l}\text { Prediction order } \\
\text { macro/femto cell }\end{array}$ & $11 / 3$ \\
\hline $\begin{array}{l}\text { Standard deviation } \\
\text { macro/femto cell }\end{array}$ & $8 / 3$ \\
\hline Thermal noise & $-174(\mathrm{dBm} / \mathrm{Hz})$ \\
\hline Noise figure & $9 \mathrm{~dB}$ \\
\hline Step-size - macro/femto cell & $0.05 / 0.1$ \\
\hline Sensing level for macro/femto cell & $-86 /-75 \mathrm{dBm}$ \\
\hline
\end{tabular}

Tab. 1. Simulation parameters.
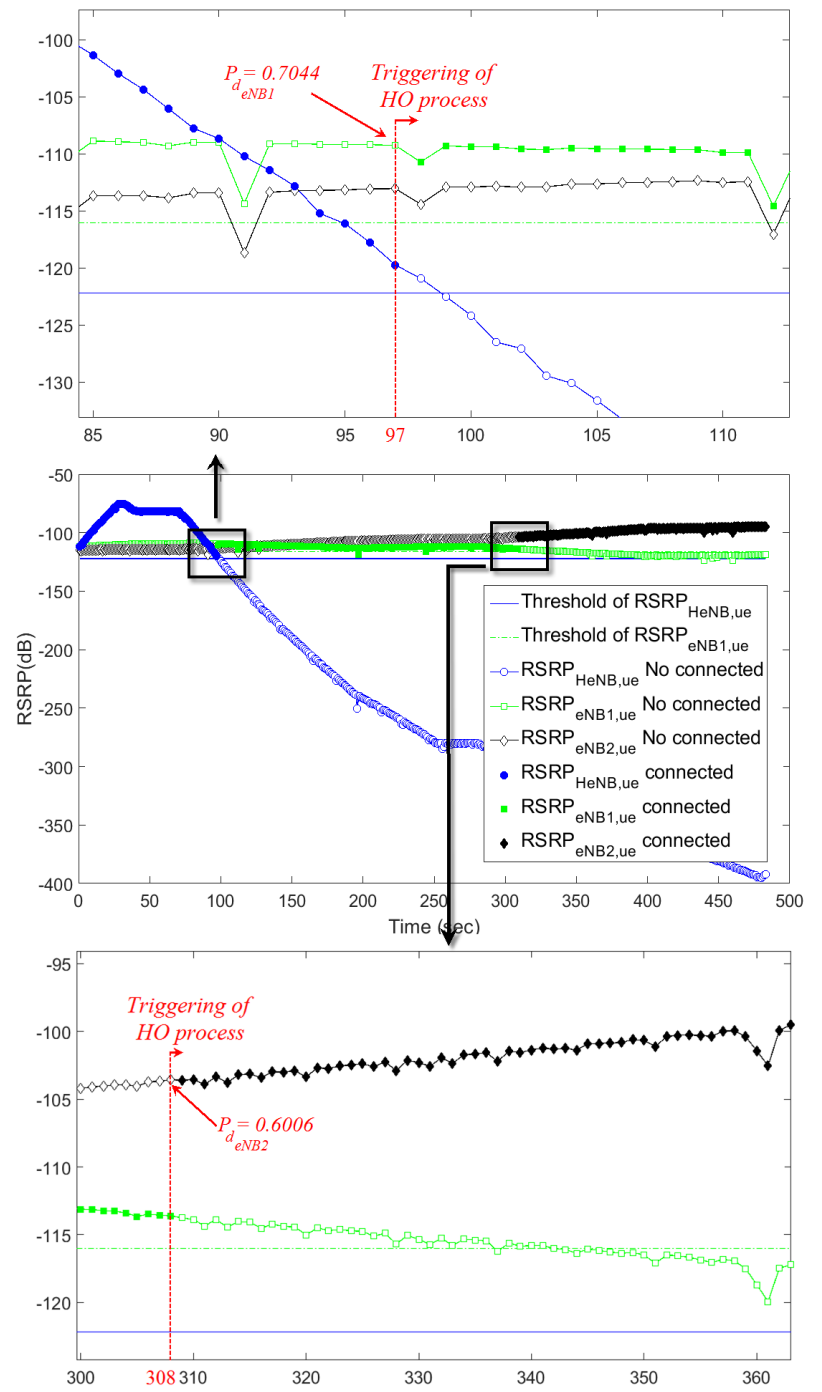

Fig. 5. LTE hard handover simulation.

The reason for calculating the sensing probabilities of these two points (Fig. 5) is to ensure the same comparison scale with the proposed method.

\subsection{LMS Process on Energy Detection}

This prediction mechanism provides an automatic method for tracking the signal probability continuously. The process starts when it harvests $p_{\text {femto }}$ samples of $R S R P_{\text {femto,ue }}$ Even so, we don't have enough time on the convergence process, fault to the small-cell size. So as to accelerate processes, we take the $p_{\text {femto }}=3$ and the step-size $\mu_{\text {femto }}=0.1$ which leads to a very low error over time (Fig. 6) and benefits a good prediction of $R S R P_{\text {femto,ue. }}$

On the other side, for each the $R S R P_{\text {macro,ue }}$ vector, we take $p_{\text {macro }}=11$ and the step-size $\mu_{\text {macro }}=0.05$. So, the condition $p_{\text {macro }}>p_{\text {femto }}$ is fixed due to large-cell size, which implies respectively, a high probability to fall brusquely into the fading, a false update of error and an inaccurate prediction header of the detection probability. We find the results in Fig. 7 and Fig. 8 of the real \& ahead prediction of the $R S R P_{\text {macro,ue }}$ for the two macro-cells. 

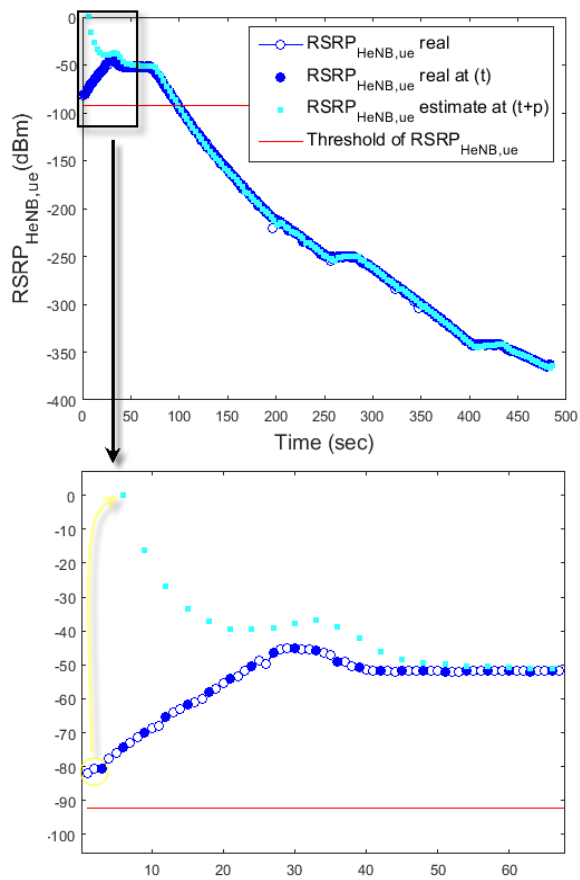

Fig. 6. Real / prediction header of $R S R P_{\text {fento,ue }}$.

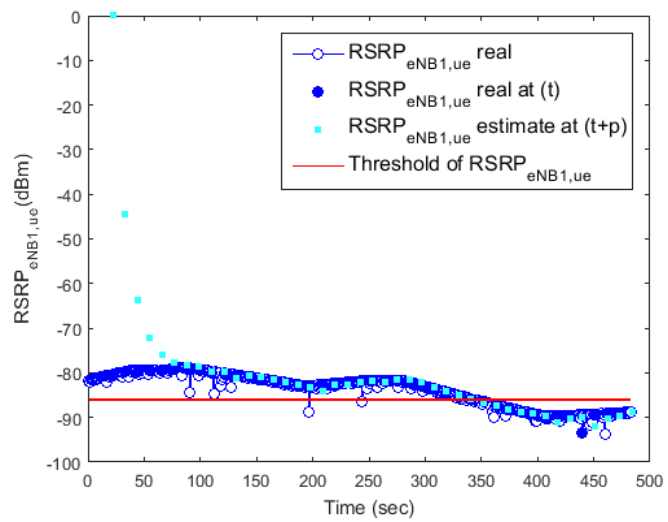

Fig. 7. Real / prediction header of $R S R P_{\mathrm{eNB} 1, \mathrm{ue}}$.

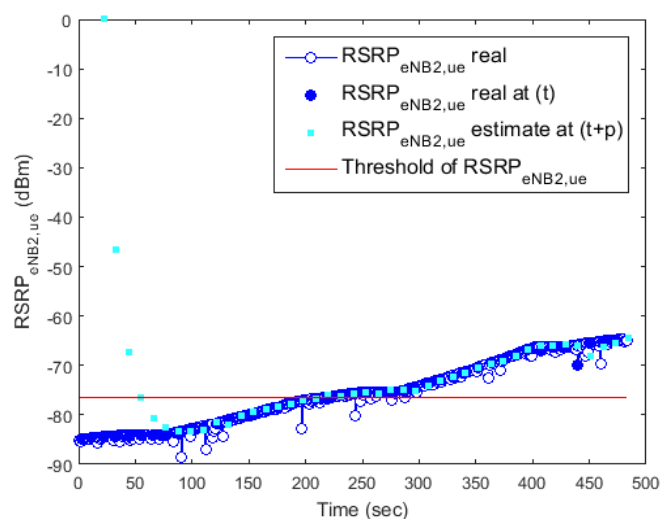

Fig. 8. Real / prediction header of $R S R P_{\mathrm{eNB} 2, \mathrm{ue}}$.

According to the proposed cycle in Fig. 3.b, we evaluate the SINR signal for each UE's position. The equations (17) and (18) as presented are used, and the results are illustrated in Fig. 9, Fig. 10 and Fig. 11.

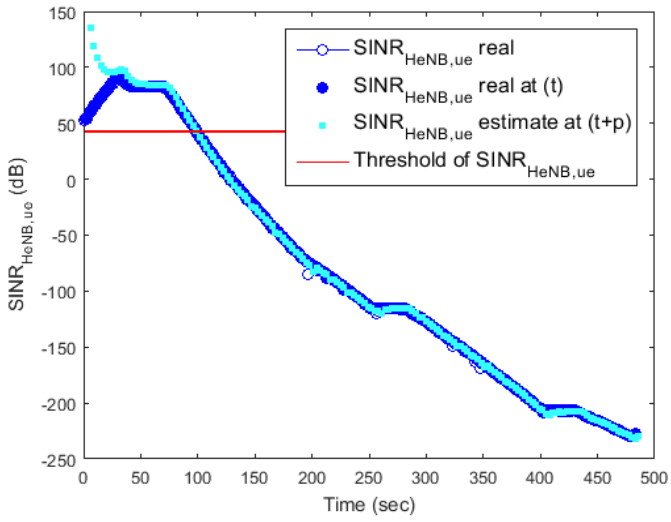

Fig. 9. Real / prediction header of $S I N R_{\text {femto,ue }}$.

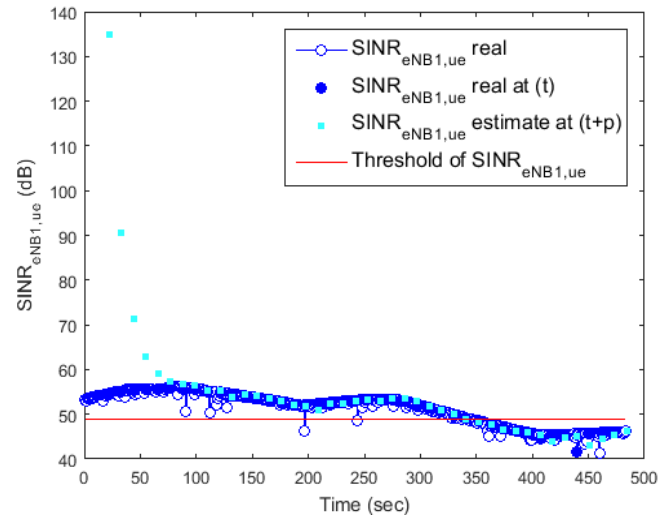

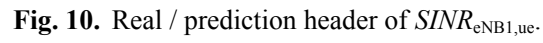

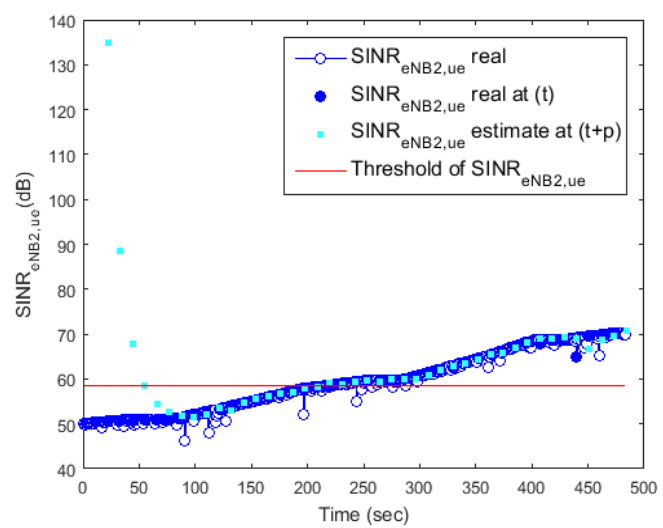

Fig. 11. Real / prediction header of $S I N R_{\mathrm{eNB} 2 \text {,ue. }}$

As depicted in Fig. 12, Fig. 13 and Fig. 14 we remark the influence on the anticipation of detection probability to start sensing others spectrums. In other words, if the ahead prediction probability value $\hat{P}_{\mathrm{d}}(t+p)$ is less than $P_{\mathrm{dth}}$ then the detection probability $P_{\mathrm{d}}(t)$ is trigged to detect other spectrums.

In Tab. 2, we summarize the detection points of real probabilities detections at $t$ to explore other probabilities of primary users in chronological order. The UE is assumed to be connected to the femto-cell at $t=1 \mathrm{~s}$, and to move toward to the edge cell. At $t=96 \mathrm{~s}$, the estimated probability of detection $\hat{P}_{\mathrm{dHeNB}}=0.5292$ is less than the 

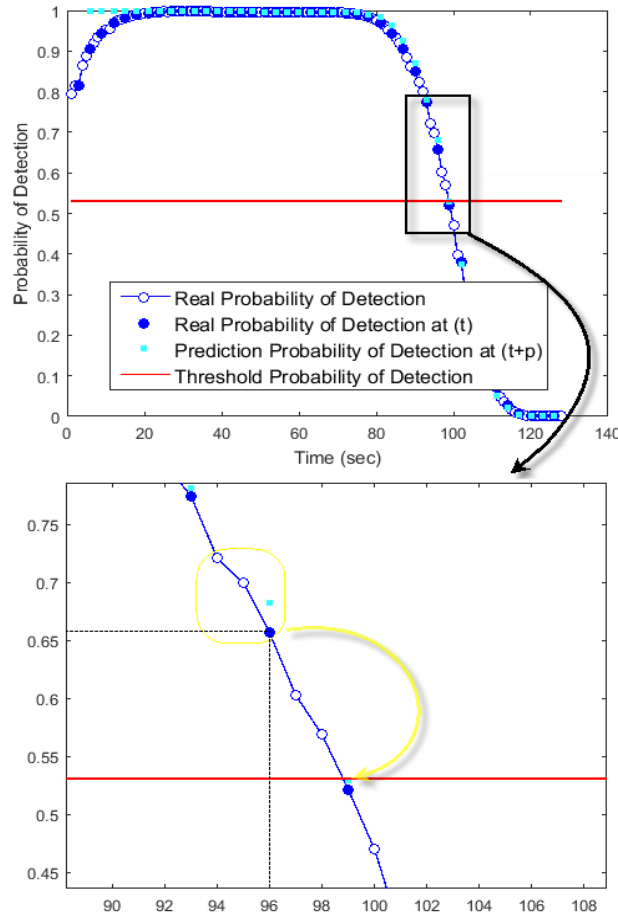

Fig. 12. Real \& anticipation on the energy detection of $P_{\mathrm{dHeNB} \text {,ue }}$
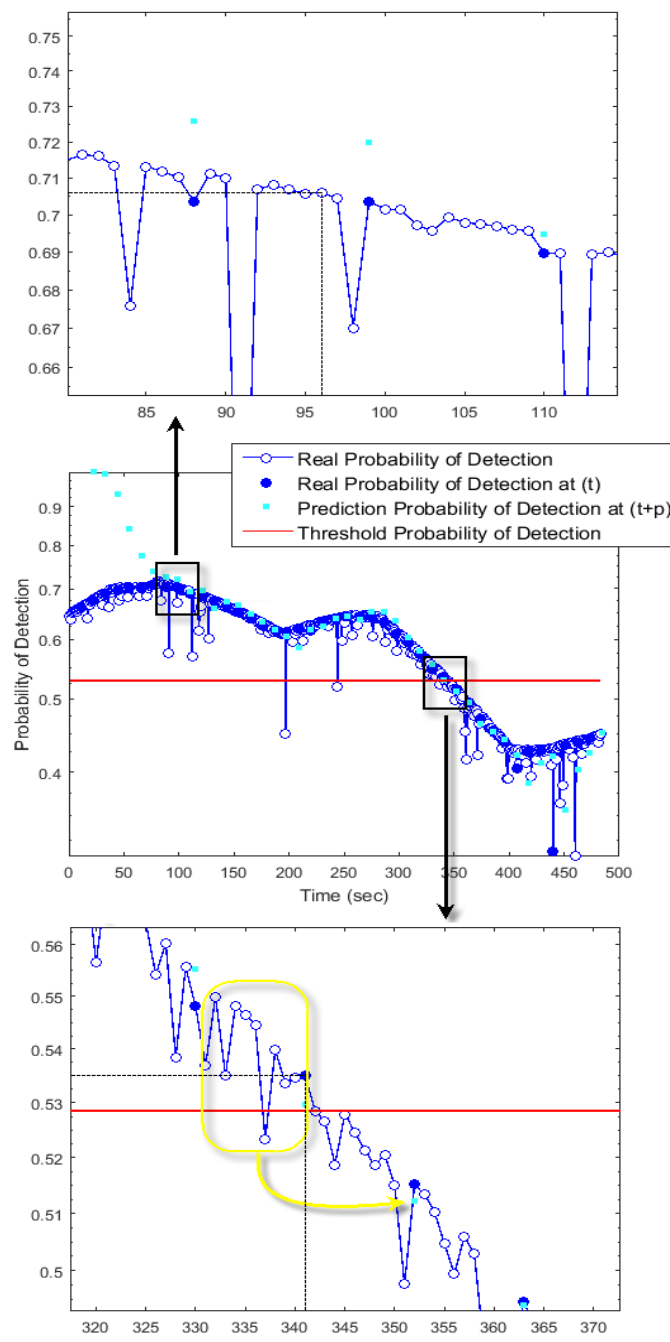

Fig. 13. Real \& anticipation on the energy detection of $P_{\mathrm{deNB} 1, \mathrm{ue}}$.
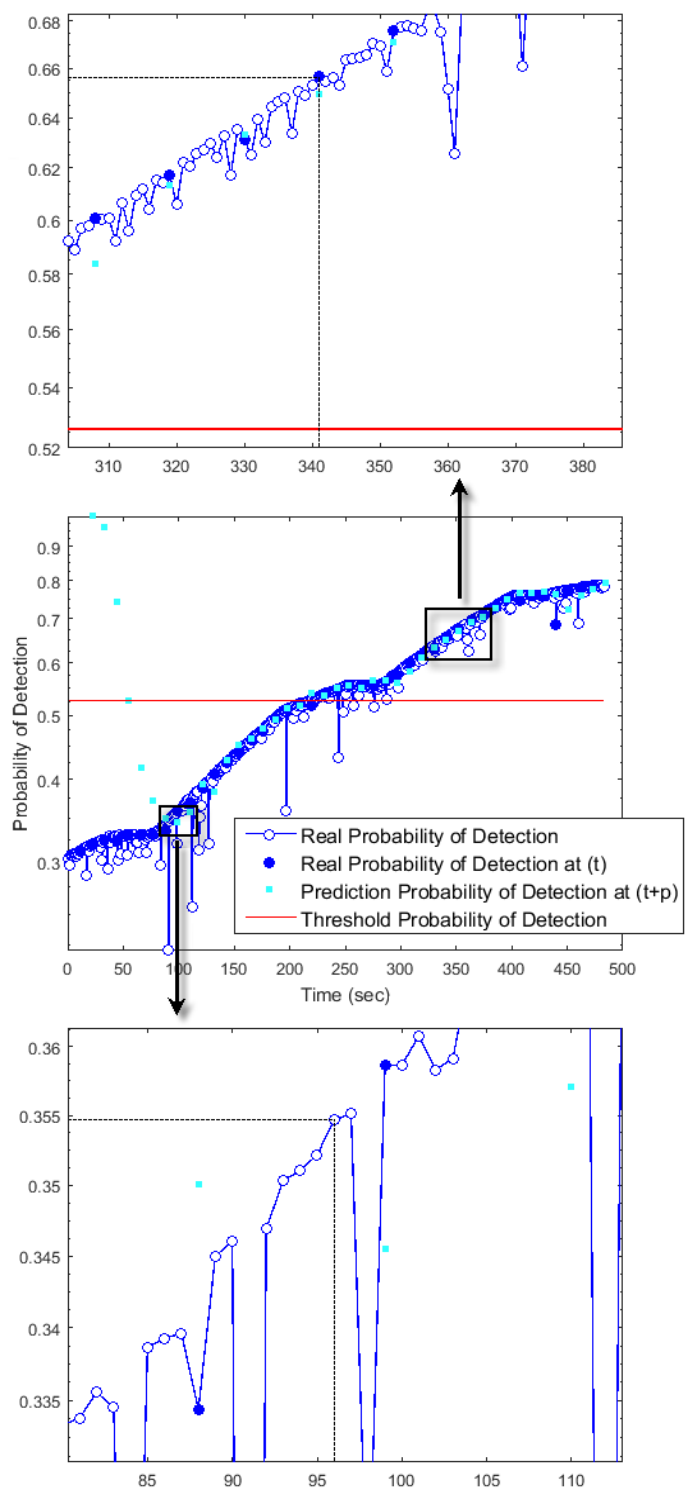

Fig. 14. Real \& anticipation on the energy detection of $P_{\mathrm{deNB} 2 \text {,ue. }}$

probability of detection threshold $P_{\mathrm{d}_{\mathrm{th}, \mathrm{HeNB}}}=0.5306$ with an error of the prediction equal to 0.0105 (weak value), thereby, the triggering to sense other spectrums at $P_{\mathrm{dHeNB}}=0.6564$ is started. So, there are two spectrums candidates; macro-cell $\# 1$ and macro-cell \#2. In order to select which one is better, the proposed algorithm calculates the detection probability $P_{\mathrm{d}}$ for both in this time $P_{\mathrm{deNB} 1}=0.7060$ and $P_{\mathrm{deNB} 2}=0.3861$. The selection is evident $P_{\mathrm{deNB} 1}$.

After connection to the macro-cell \#1, the UE keeps moving until $t=341 \mathrm{~s}$ where the detection of the macrocell \#2 spectrum is obvious $\left(P_{\mathrm{deNB}_{\mathrm{e}}}>P_{\mathrm{d} \mathrm{HeNB}}\right)$ with an excellent precision equal to $99.7 \%$. Whereas, after $t=341 \mathrm{~s}$, the process to find other spectrums will be not triggering until the end of simulation, because $\hat{P}_{\mathrm{d}_{\mathrm{eNB}} 2}$ value will be always staying superior to $P_{\mathrm{dth}, \mathrm{eNB} 2}$, we can confirm this by comparing $P_{\mathrm{deNB} 2}=0.7830$ with $P_{\mathrm{dth}, \mathrm{NB} 2}=0.5261$ at $t=483 \mathrm{~s}$, where the UE is remained always connected to the macrocell \#2. 


\begin{tabular}{|c|c|c|c|c|c|}
\hline$t(\mathrm{~s})$ & $P_{\mathrm{d}}$ & $P_{\mathrm{d}_{\mathrm{th}}}$ & $P_{\mathrm{d}}(t+p)$ & $\hat{P}_{\mathrm{d}}(t+p)$ & $\begin{array}{c}\text { Error of } \\
\text { precision }\end{array}$ \\
\hline 1 & \multicolumn{5}{|c|}{ Connect to femto-cell } \\
\hline \multicolumn{6}{|c|}{$\begin{array}{c}\vdots \\
\text { Femto-cell }\end{array}$} \\
\hline 96 & 0.6564 & 0.5306 & 0.5215 & 0.5292 & 0.0105 \\
\hline \multicolumn{6}{|c|}{ Detect others spectrums before Handoff } \\
\hline \multicolumn{6}{|c|}{ macro-cell \#1 } \\
\hline 96 & 0.7060 & & & & \\
\hline \multicolumn{6}{|c|}{ macro-cell \#2 } \\
\hline 96 & 0.3547 & & & & \\
\hline \multicolumn{6}{|c|}{ Connect to macro-cell \#1 } \\
\hline \multicolumn{6}{|c|}{$\begin{array}{c}\vdots \\
\text { macro-cell \#1 }\end{array}$} \\
\hline 341 & 0.5351 & 0.5286 & 0.5152 & 0.5122 & 0.0030 \\
\hline \multicolumn{6}{|c|}{$\frac{1}{\text { Detect another spectrum before Handoff }}$} \\
\hline \multicolumn{6}{|c|}{ femto-cell } \\
\hline 341 & 0 & & & & \\
\hline \multicolumn{6}{|c|}{ macro-cell \#2 } \\
\hline 341 & 0.6566 & & & & \\
\hline \multicolumn{6}{|c|}{ Connect to macro-cell \#2 } \\
\hline \multicolumn{6}{|c|}{$\begin{array}{c}\vdots \\
\text { macro-cell \#2 }\end{array}$} \\
\hline 483 & 0.7830 & 0.5261 & & & \\
\hline
\end{tabular}

Tab. 2. Chronological order of the simulation study.

\subsection{Algorithms Evaluation}

For the evaluation the proposed algorithm, we compare with the conventional HO algorithm.

Figure 15 presents the curve sensing probability HeNB for both methods. At $t=96 \mathrm{~s}$ and $t=97 \mathrm{~s}$ are the times to trigger the $\mathrm{HO}$ process for the proposed and classical algorithms with the first sensing probability to handoff on eNB1 $\quad P_{\mathrm{HO} 1}=P_{\mathrm{deNB}_{\mathrm{eN}}}=0.7060 \quad$ and $P_{\mathrm{HO} 1}^{\prime}=P_{\mathrm{d}_{\mathrm{eNB} 1}}=0.7044$ respectively.

On the second triggering (Fig. 16) the standard HO process is triggered too early before the link down of macro-cell\#1, although the adjustment of the constant $\mathrm{HOM}$ is at its maximum $\left(P_{\mathrm{HO} 2}^{\prime}=P_{\mathrm{deNB}^{2}}=0.6006\right)$. So in the proposed algorithm, the sensing probability of triggering is accurate $\left(P_{\mathrm{HO} 2}=P_{\mathrm{deNB} 2}=0.6566\right)$.

\subsection{Other Simulations}

To verify the validity of the LMS process on energy detection we use two other traces pedestrian mobility of METIS [40] in the same topology model (Fig. 17) and simulation parameters (Tab. 1).

So, the pedestrian \#2 (UE2) begins to move in the first macro cell by crossing the femto-cell and finishes its trajectory in the first macro-cell (Fig. 17). However, in the classical HO process (Fig. 18) the first triggering will occur at $t=125 \mathrm{~s}$ (Fig. 19).
The second triggering is started at $t=243 \mathrm{~s}$ for changing the sector eNB1 to HeNB (Fig. 20).

Let's see the impact of LMS process on sensing probability of spectrum (Fig. 21). At $t=117 \mathrm{~s}$ the sensing probability for triggering the first $\mathrm{HO} P_{\mathrm{HO} 1}$ is sensed to HeNB $\left(P_{\mathrm{dHeNB}}=0.4794, P_{\mathrm{deNB} 2}=0.3258\right)$. At $t=246 \mathrm{~s}$ the second probability of detection for the $\mathrm{HO}$ triggering $P_{\mathrm{HO} 2}$ is sensed to eNB1 $P_{\mathrm{deNB} 1}=0.6193, P_{\mathrm{deNB} 2}=0.33056$ ).

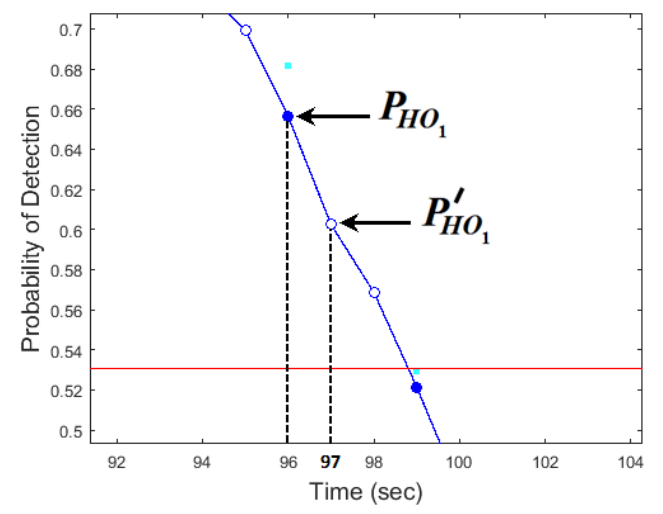

Fig. 15. Triggering the first HO process (Conventional \& proposed algorithms).

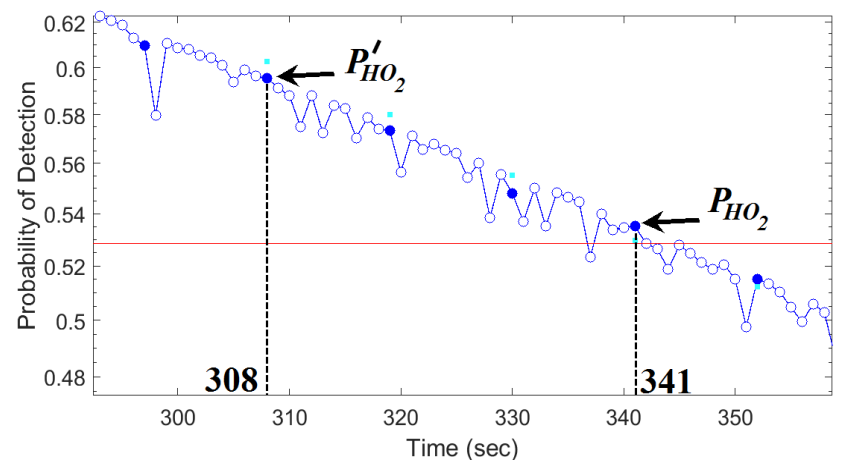

Fig. 16. Triggering the second HO process (Conventional \& proposed algorithms).

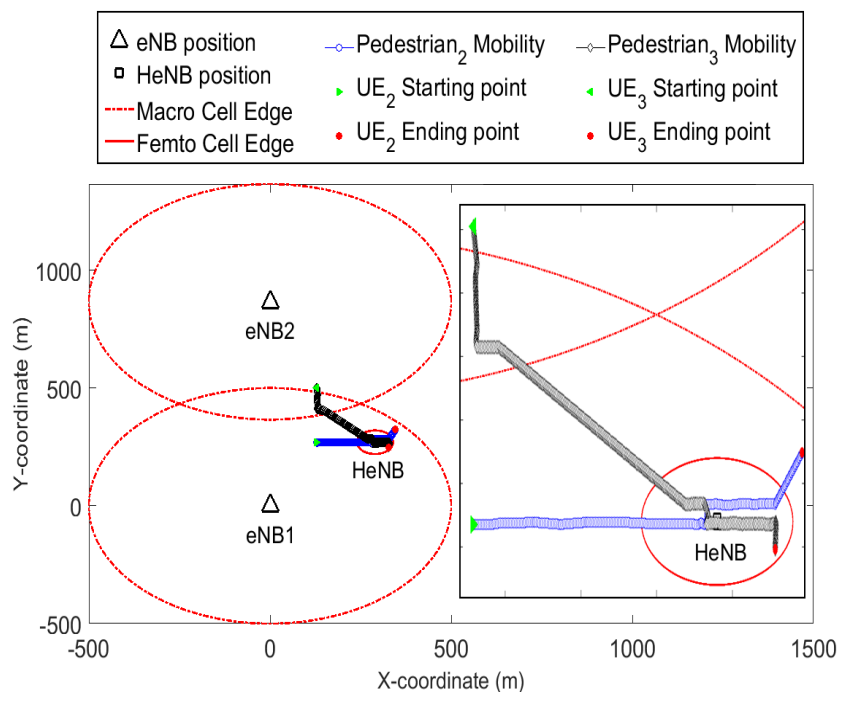

Fig. 17. Pedestrian mobility of METIS in the same topology. 


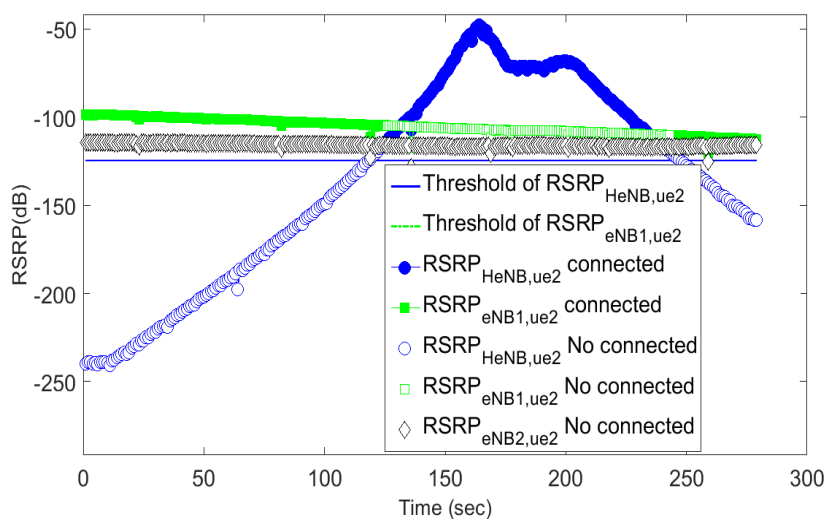

Fig. 18. Conventional HO process for UE2.

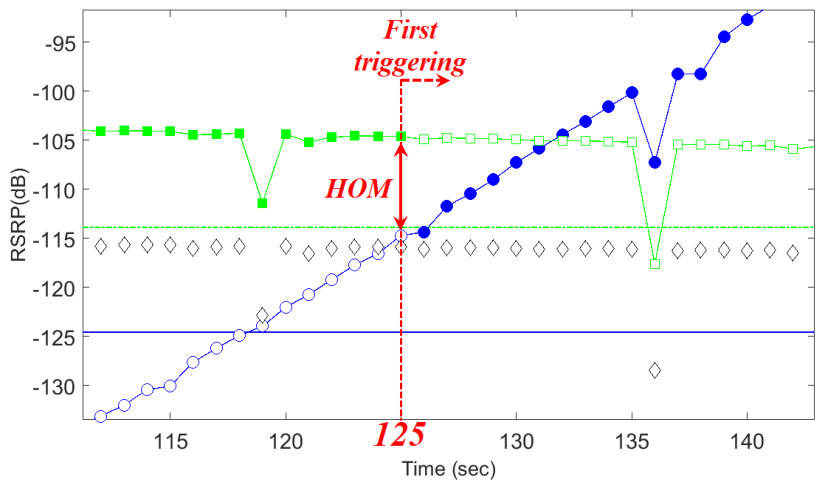

Fig. 19. First triggering of $\mathrm{HO}$ process for UE2.

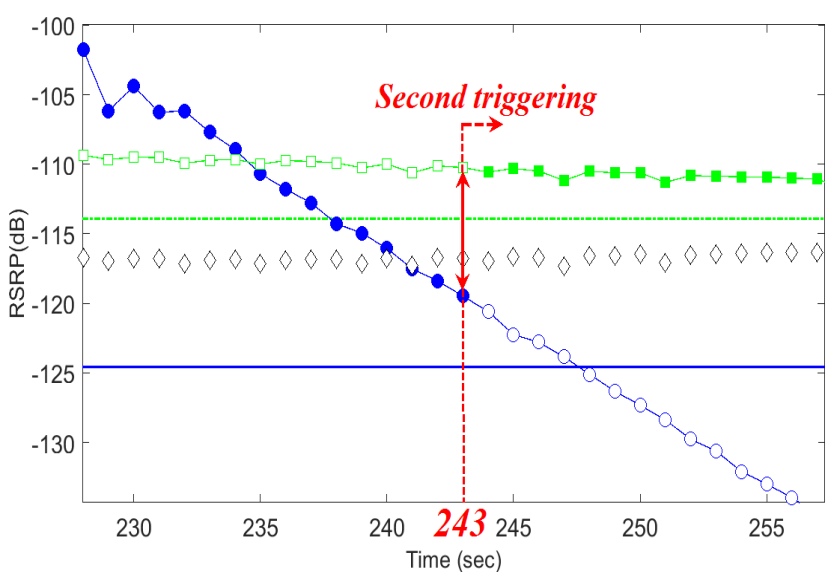

Fig. 20. Second triggering of HO process for UE2.

For the pedestrian \#3 (UE3): He starts to move in the second macro-cell until the femto-cell crossing the first macro-cell. As plotted in Fig. 22, where, it presents the conventional HO. There are two points of triggering. The first will occur at $t=181 \mathrm{~s}$ after the link down of eNB2 (Fig. 23) and at $t=279 \mathrm{~s}$, there is the second time for changing sector eNB1 to HeNB (Fig. 24).

Let us now see the sensing probability. As presented in Fig. 25 at $t=121 \mathrm{~s}$ the probability of detection for triggering the first $\mathrm{HO} P_{\mathrm{HO} 1}$ is sensed to eNB1 $\left(P_{\mathrm{deNB} 1}=0.6534 ; P_{\mathrm{d} \mathrm{HeNB}}=8.6926 \times 10^{-10}\right)$.
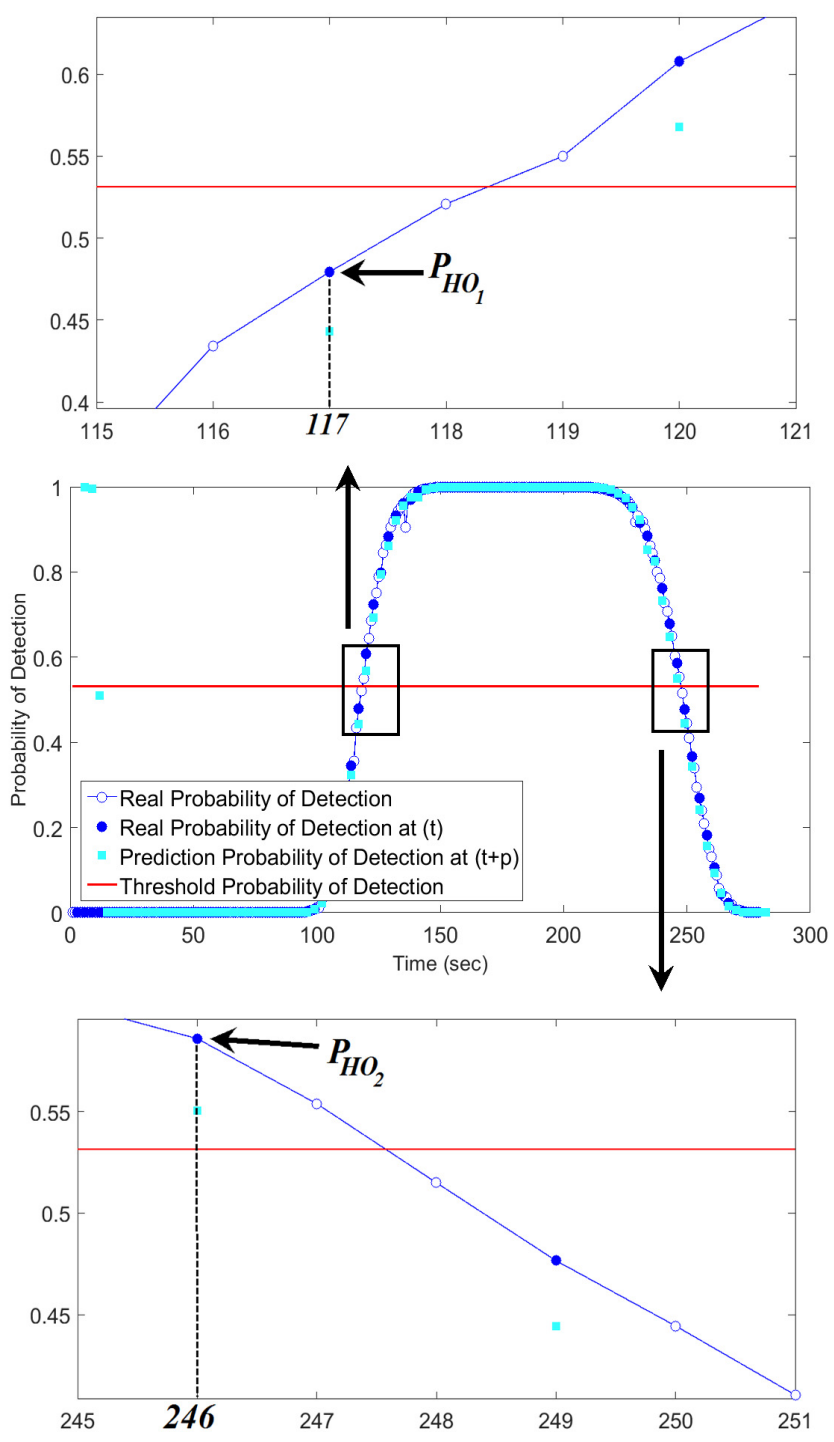

Fig. 21. Sensing probability of HO process (proposed method).

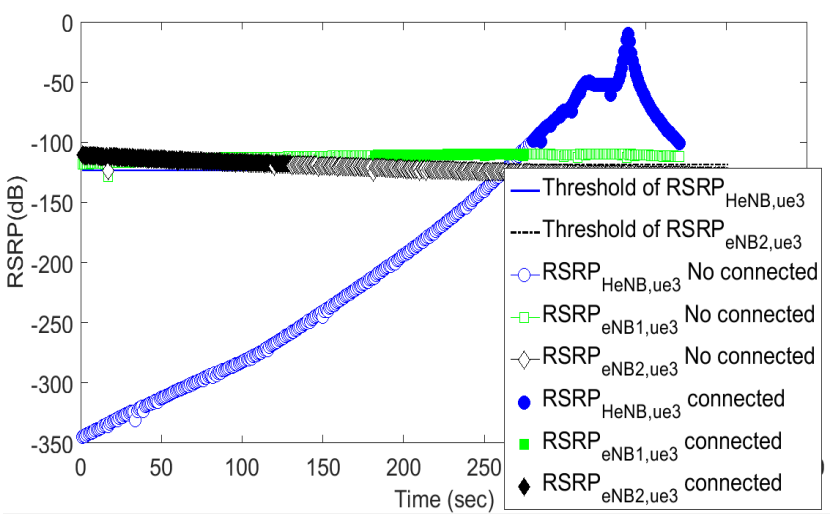

Fig. 22. Conventional HO process for UE3.

The second probability of detection for the $\mathrm{HO}$ triggering $P_{\mathrm{HO} 2}$ (Fig. 26) is sensed to HeNB at $t=261 \mathrm{~s}$ $\left(P_{\mathrm{deNB} 2}=0.3448 ; P_{\mathrm{dHeNB}}=0.4713\right)$. 


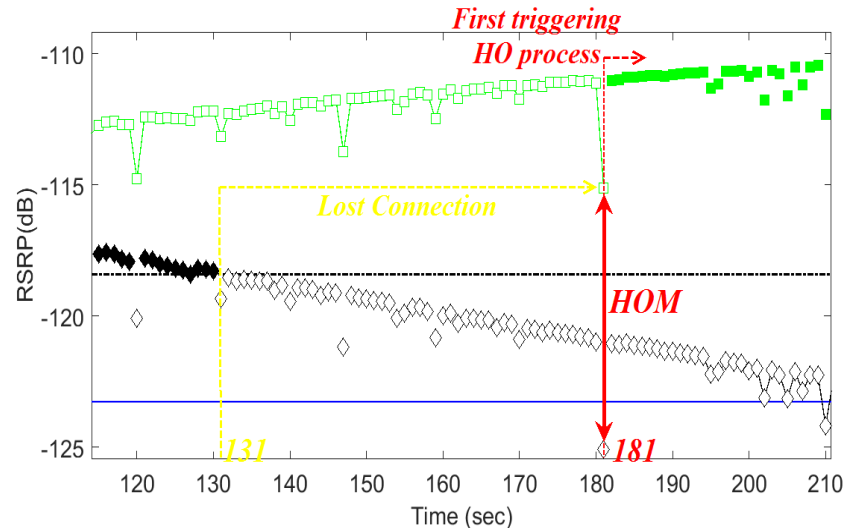

Fig. 23. First triggering of HO process for UE3.

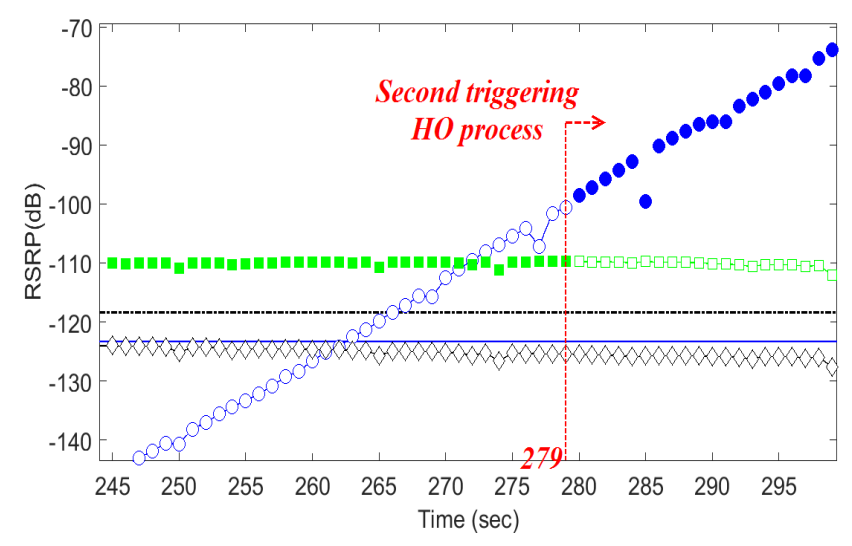

Fig. 24. Second triggering of HO process for UE3.

\section{Conclusion}

The primary objective of this paper is to improve in real-time the spectrums sensing in a heterogeneous LTE network. Our study leads to see the effectiveness of the LMS process on the energy detection mechanism in order to predicate the detection probability of the spectrum at $(t+p)$ and to search other spectrums in the surrounding by calculating the detection probability at $t$ and to take the right decision by comparing which have the best sensing probability. In addition, this study allows seeing another appearance of traditional process on the triggering of the handover. The simulation results show that the proposed algorithm attains the best performance with the excellent precision on future spectrum sensing in real environment contrary to the conventional $\mathrm{HO}$ process that depends on several adjustment of HOM and TTT. Equally, the numbers of HOM values are limited which has a crippling impact on LTE network.

An interesting work that should follow this research is to investigate the impact of this algorithm by increasing the femto-cells in macro-cell, and also, to introduce an adaptive variable step-size method on LMS filter that allows the auto-adaptive sensing.

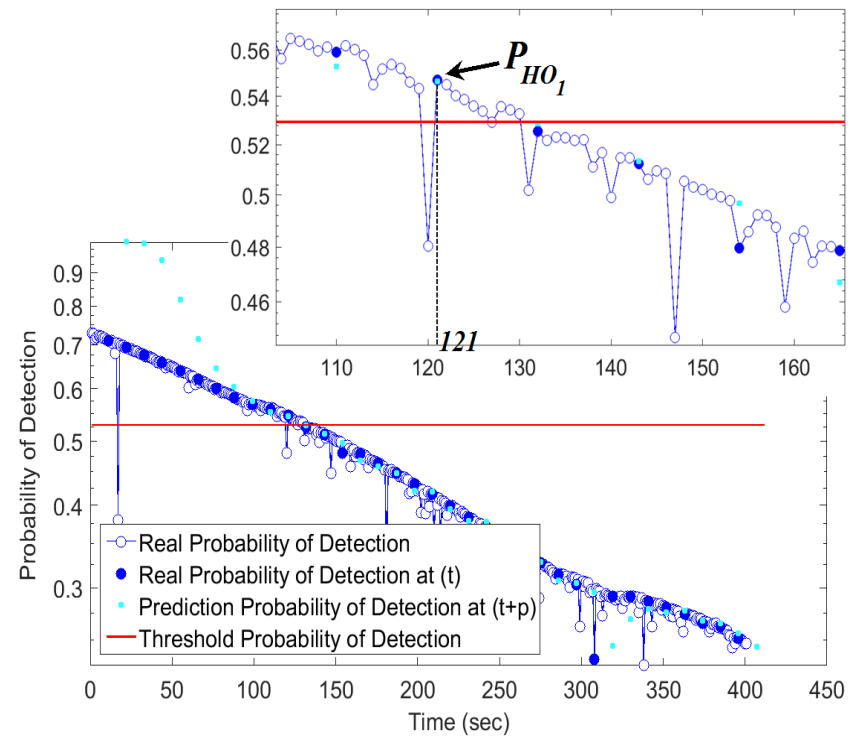

Fig. 25. First triggering of $\mathrm{HO}$ process (proposed method).

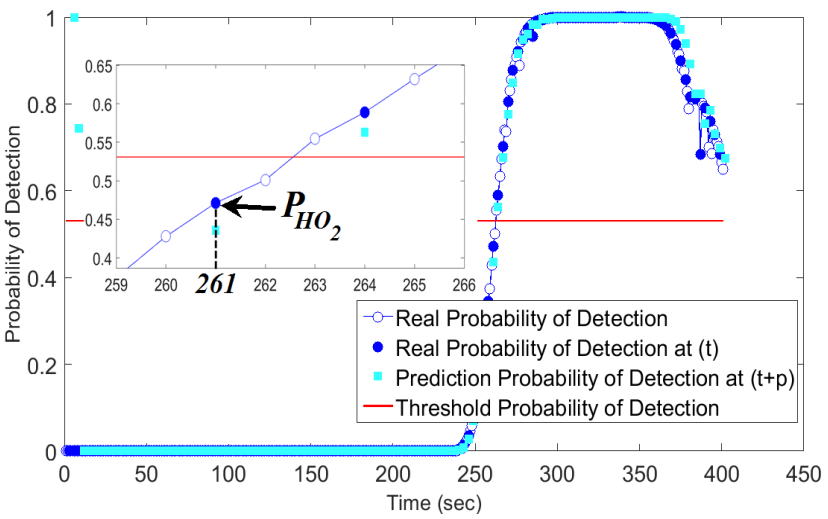

Fig. 26. Second triggering of HO process (proposed method).

\section{References}

[1] HOLMA, H., TOSKALA, A. LTE for UMTS - OFDMA and SCFDMA Based Radio Access. Chippenham (UK): John Wiley \& Sons, Ltd. 2009. ISBN-13: 978-0-470-99401-6

[2] GÓDOR, G., JAKÓ Z., KNAPP Á., et al. A survey of handover management in LTE-based multi-tier femto-cell networks: Requirements, challenges and solutions. ELSEVIER Computer Networks, 15 January 2015, vol. 76, p. 17-41. DOI: 10.1016/j.comnet.2014.10.016

[3] SESIA, S., TOUFIK, I., BAKER, M. LTE - The UMTS Long Term Evolution: From Theory to Practice. $2^{\text {nd }}$ ed. Chippenham (UK): John Wiley \& Sons, Ltd. 2011. ePDF ISBN-13: 9780470978511

[4] 3GPP, Technical Report, 3rd Generation Partnership Project; Technical Specification Group Radio Access Network; Physical Layer Aspects for Evolved Universal Terrestrial Radio Access (UTRA) (Release 7) TR25.814 V7.1.0. [Online] Cited 09-2006. 132 pages. Available at: www.qtc.jp/3GPP/Specs/25814-710.pdf

[5] GHOSH, A., RATASUK R., MONDAL B., et al. LTE-advanced: next generation wireless broadband technology. IEEE Wireless Communications, June 2010, vol. 17, no. 3, p. 10-22. DOI: 10.1109/MWC.2010.5490974 
[6] GHOSH, A., RATASUK R. Essentials of LTE and LTE-A. Cambridge (UK): Cambridge University Press. 2011. ISBN: 9781139098021

[7] AFROZ, F., SANDRASEGARAN, K. GHOSHAL, P. Performance analysis of PF, M-LWDF and EXP/PF packet scheduling algorithms in 3GPP LTE downlink. In Australasian Telecommunication Networks and Applications Conference (ATNAC). Southbank (VIC, Australia), 26-28 Nov. 2014, p. 87-92. DOI: 10.1109/ATNAC.2014.7020879

[8] AFROZ, F. Research in $4 G$ Mobile Network. MES Project, University of Technology, Sydney, 2014.

[9] AFROZ, F., SUBRAMANIAN, R., HEIDARY, R., et al. SINR, RSRP, RSSI and RSRQ measurements in Long Term Evolution Networks. International Journal of Wireless \& Mobile Networks $(I J W M N)$, August 2015, vol. 7, no. 4, p. 113-123. DOI: 10.5121/ijwmn.2015.7409

[10] SESIA S., TOUFIK I., BAKER, M. LTE- The UMTS Long Term Evolution: From Theory to Practice. Chichester (UK): John Wiley \& Sons, Ltd. 2009. ISBN-13: 9780470697160

[11] KIM, R. Y., JUNG, I., YANG, X. Y. et al. Advanced handover schemes in IMT-advanced systems [WiMAX/LTE Update]. IEEE Communications Magazine, August 2010, vol. 48, no. 8, p. 78-85. DOI: 10.1109/MCOM.2010.5534590

[12] LUAN, L., WU, M., SHEN, J. et al. Optimization of handover algorithms in LTE high-speed railway networks. International Journal of Digital Content Technology and Its Applications (JDCTA), March 2012, vol. 6, no. 5, p. 79-87. DOI: 10.4156/jdcta.vol6.issue 5.10

[13] TSAI, K-L., LIU, H-Y., LIU, Y-W. Using fuzzy logic to reduce ping-pong handover effects in LTE networks. Soft Computing, May 2016, vol. 20, no. 5, p. 1683-1694 DOI: $10.1007 / \mathrm{s} 00500-$ $015-1655-z$

[14] JEONG, B., SHIN, S., JANG, I., et al. A smart handover decision algorithm using location prediction for hierarchical macro/femtocell networks. In IEEE Vehicular Technology Conference (VTC Fall). San Francisco (CA, USA), 5-8 September 2011, p. 1-5. DOI: 10.1109/VETECF.2011.6093060

[15] WU, C-S., CHU, Y-S., FANG, C-H. The periodic scan and velocity decision handover scheme for next generation femtocell/macro-cell overlay networks. In International Conference on ICT Convergence (ICTC). Jeju (South Korea), 14-16 October 2013, p. 201-206. DOI: 10.1109/ICTC.2013.6675340

[16] CHANG, C-W., LIN, Y-H., JAN, R-H., et al. Efficient measurement procedure for handover in LTE femto-cell networks. In International Conference on Selected Topics in Mobile and Wireless Networking (iCOST). Avignon (France), 2-4 July 2012, p. 119-123. DOI: $10.1109 /$ iCOST.2012.6271278

[17] SAHAI, A., HOVEN, N., MISHRA, S-M., et al. Fundamental Tradeoffs in Robust Spectrum Sensing for Opportunistic Frequency Reuse. Dept. of Electrical Engg. and Computer Science, Univ. of California, Berkeley. [Online] Cited 2006. 75 p. Available at: http://www.eecs.berkeley.edu/ sahai/Papers/CognitiveTechReport 06.pdf

[18] AKYILDIZ, I. F., LO, B. F., BALAKRISHNAN, R. Cooperative spectrum sensing in cognitive radio networks: A survey. Physical Communication, March 2011, vol. 4, no. 1, p. 40-62. DOI: 10.1016/j.phycom.2010.12.003

[19] AKYILDZ, I. F., LEE, W. Y., VURAN, M. C., et al. NeXt generation/dynamic spectrum access/cognitive radio wireless networks: A survey. Computer Networks, 15 September 2006, vol. 50, no. 13, p. 2127-2159. DOI: 10.1016/j.comnet.2006.05.001

[20] LETAIEF, K. B., ZHANG, W. Cooperative Spectrum Sensing. Chapter in Cognitive Wireless Communications Networks. Eds. Hossain, E., Bhargava, V. Berlin (Germany): Springer, 2007.
P. 115-138. Available at: http: //link.springer.com/ chapter/10.1007\%2F978-0-387-68832-9 4

[21] GENTNER, C., GROH, I., SAND, S., et al. False alarm and detection probability for NLOS detection in LTE environments. In 8th International Workshop on Multi-Carrier Systems \& Solutions (MC-SS). Herrsching (Germany), 3-4 May 2011, p. 1-5. DOI: 10.1109/MC-SS.2011.5910721

[22] FODOR, V., GLAROPOULOS, I., PESCOSOLIDO, L. Detecting low-power primary signals via distributed sensing to support opportunistic spectrum access. In IEEE International Conference on Communications ICC '09. Dresden (Germany), 14-18 June 2009, p. 1-6. DOI: $10.1109 /$ ICC.2009.5198909

[23] MAZROOEI SEBDANI, M., JAVAD OMIDI, M. Detection of an LTE signal based on constant false alarm rate methods and Constant Amplitude Zero Autocorrelation sequence. In International Conference on Intelligent and Advanced Systems (ICIAS). Kuala Lumpur (Malaysia), 15-17 June 2010, p. 1-6. DOI: 10.1109/ICIAS.2010.5716190

[24] YOO, S.-J. Efficient traffic prediction scheme for real-tTime VBR MPEG video transmission over high-speed networks. IEEE Transactions on Broadcasting, March 2002, vol. 48, no. 1, p. 10 to 18. DOI: $10.1109 / 11.992849$

[25] JANSEN, T., BALAN, I., TURK, J., et al. Handover parameter optimization in LTE self-organizing networks. In IEEE 72nd Conference on Vehicular Technology Conference Fall (VTC 2010Fall). Ottawa (ON, Canada), 6-9 September 2010. p. 1-5. DOI: 10.1109/VETECF.2010.5594245

[26] DASHTI, M., CHEN, J. Handover strategies between femto and macro-cells, the results of this work submitted in July 2014 to the IEEE International Conference on Computer Communications (IEEE INFOCOM 2014). 11 p. Available at: iplan.project.citilab.fr /files/D2-4-heterogeneous.pdf

[27] 3GPP, Technical Specification Group Radio Access Network; Evolved Universal Terrestrial Radio Access (E-UTRA): Physical layer; Measurements (Release 8) TS 36.214 V8.0.0. [Online] Cited 09-2007. 11 pages. Available at: www.qtc.jp/3GPP/Specs/36214800.pdf

[28] ANPALAGAN, A., BENNIS M., VANNITHAMBY, R. Design and Deployment of Small Cell Networks. Cambridge (UK): 2016. ISBN-13: 978-1-107-05671-8

[29] BECVAR, Z., MACH., P, VONDRA, M. Handover Procedure in Femto-cells. Chapter 9 in Femto-cell Communications and Technologies: Business Opportunities and Deployment Challenges. Eds. Saeed, R-A., Chaudhari B-S., Mokhtar, R-A. Hershey (USA): Information Science Reference IGI Global. January 2012. P. 157-179. DOI: 10.4018/978-1-4666-00928.ch010

[30] VARDHAN, C.S., RATNAM, D.V., BHAGYASREE, N., et al. Analysis of path loss models of $4 \mathrm{G}$ femto-cells. In Eleventh International Conference on Wireless and Optical Communications Networks (WOCN). Vijayawada (India), 11-13 Sept. 2014, p. 1-6. DOI: 10.1109/WOCN.2014.6923071

[31] ALEXIOU, A., BOURAS, C., KOKKINOS, V., et al. Interference behavior of integrated femto and macro-cell environments. In 2011 IFIP Wireless Days (WD). Niagara Falls (ON, Canada), 10-12 Oct. 2011, p. 1-5. DOI: 10.1109/WD.2011.6098161

[32] RAPPAPORT, T. S. Wireless Communications: Principles and Practice. $2^{\text {nd }}$ ed. NJ (USA): Prentice Hall, 2002. ISBN-13: 9780130422323

[33] ADARDOUR, H. E., MELIANI, M., HACHEMI, M. H. Estimation of the spectrum sensing for the cognitive radios: Test analysing using Kalman filter. Wireless Personal Communications, September 2015, vol. 84, no. 2, p. 1535-1549. DOI: $10.1007 / \mathrm{s} 11277-015-2701-\mathrm{y}$ 
[34] SURESH BABU, R., SUGANTHI, M. Review of energy detection for spectrum sensing in various channels and its performance for cognitive radio applications. American Journal of Engineering and Applied Sciences, 2012, vol. 5, no. 2, p. 151-156. DOI: 10.3844/ajeassp.2012.151.156

[35] WU, S-W., ZHU, J-K., QIU, L., et al. SNR-based weighted cooperative spectrum sensing in cognitive radio networks. Journal of China Universities of Posts and Telecommunications, April 2010, vol. 17 , no. 2 , p. 1-7. DOI: 10.1016/S1005-8885(09)60437-4

[36] DIGHAM, F. F., ALOUINI, M. S., SIMON, M. K. On the energy detection of unknown signals over fading channels. In IEEE International Conference on Communications 2003 (ICC '03). Anchorage (USA), 11-15 May 2003, vol. 5, no. 1, p. 3575-3579. DOI: 10.1109/ICC.2003.1204119

[37] GRADSHTEYN, I. S., RYZHIK, I. M. Table of Integrals, Series, and Products. $5^{\text {th }}$ ed. Academic Press, January 1994. ISBN-13: 978-0122947551

[38] NUTTALL, A. H. Some integrals involving the $\mathrm{Q}_{\mathrm{M}}$ function (Corresp.). IEEE Transactions on Information Theory, vol. 21, no. 1, p. 95-96. DOI: 10.1109/TIT.1975.1055327

[39] GRADSHTEYN, I. S., RYZHIK, I. M. Table of Integrals, Series, and Products. $6^{\text {th }}$ ed. San Diego (CA, USA): Academic Press, July 2000. ISBN-10: 0122947576

[40] ZHANG, X., XIAO, Z., BABU MAHATO, S, et al. Dynamic user equipment-based hysteresis-adjusting algorithm in LTE femtocell networks. IET Communications, 27 November 2014, vol. 8, p. 3050-3060 DOI: 10.1049/iet-com.2014.0277

[41] BECVAR, Z., MACH, P. Adaptive hysteresis margin for handover in femtocell networks. In 6th International Conference on Wireless and Mobile Communications (ICWMC). Valencia (Spain), 20-25 September 2010, p. 256-261. DOI: 10.1109/ICWMC.2010.17

[42] AZIZ, D., SIGLE, R. Improvement of LTE handover performance through interference coordination. In IEEE 69th Vehicular Technology Conference (VTC). Barcelona (Spain), 26-29 April 2009, p. 1-5. DOI: 10.1109/VETECS.2009.5073597

[43] LIN, C-C., SANDRASEGARAN, K., REEVES, S. Handover algorithm with joint processing in LTE-advanced. In 9th International Conference on Electrical Engineering/Electronics, Computer, Telecommunications and Information Technology (ECTI-CON). Phetchaburi (Thailand), 16-18 May 2012, p. 1-4. DOI: 10.1109/ECTICon.2012.6254240

[44] LIN, C-C., SANDRASEGARAN, K., ADIBAH MOHD RAMLI, H., et al. Optimized performance evaluation of LTE hard handover algorithm with average RSRP constraint. International Journal of Wireless \& Mobile Networks (IJWMN), April 2011, vol. 3, no. 2, p. 1-16. DOI: $10.5121 /$ ijwmn.2011.3201

[45] WANG, Y-C., CHUANG, C-A. Efficient eNB deployment strategy for heterogeneous cells in 4G LTE systems. Computer Networks, 14 March 2015, vol. 79, p. 297-312. DOI: 10.1016/j.comnet.2015.01.013
[46] Mobile and wireless communications Enablers for Twenty-twenty (2020) Information Society (METIS). Available at: https://www.metis2020.com/documents/simulations/

[47] 3GPP, LTE; Evolved Universal Terrestrial Radio Access (EUTRA); Radio Resource Control (RRC); Protocol specification (3GPP TS 36.331 version 9.1.0 Release 9) TS 136331 V9.1.0. [Online] Cited 02-2010. 235 pages. Available at: www.3gpp.org/dynareport/36331.htm

\section{About the Authors ...}

Mohammed Hicham HACHEMI received his Engineer degree in Telecommunication Engineering from the University of Saida, Algeria in 2007, the subject of the final year project was on Studies \& Realization of the Detection of a Gas Leak by SMS. This project was presented in the casting of the emission Stars of Science in Tunisia. It was ranked among the 16 inventions in the Arab World. From 2008 to 2011, he receives the Magister degree in the doctoral school entitled Science, Information Technology and Telecommunications from the Faculty of Engineering, Sidi Bel Abbes University, Algeria. From 2012, he integrated STIC laboratory as a member and Ph.D. student at the University of Tlemcen, Algeria, and his current research activities involve Wireless Communications Networks, Cognitive Radio, Macro \& Femto-cell networks, Prediction of signals.

Mohammed FEHAM received his Dr. Eng. degree in Optical and Microwave Communication from IRCOM, University of Limoges, France in 1987, and his Ph.D. in Science from the University of Tlemcen, Algeria in 1996. Since 1987, he has been an Assistant Professor and Professor of Microwave and Communication Engineering. He has served on the Scientific Council, president of several conferences, president of the scientific committees of Electronics and GEE departments, expert of several research agencies, person in charge for several masters and doctorates. His research interests include telecommunication systems and mobile networks and services.

Harroun Errachid ADARDOUR received his Master degree in Components and Electronics Systems for Telecommunications from the University of Tlemcen, Algeria in 2012. Member of STIC laboratory at the University of Tlemcen and Ph.D. student in System and Networks of Telecommunication. His research topic is Wireless Communications in the Cognitive Radio Networks. 